\title{
Globalisation of Teaching and Learning Methodologies in secondary Education
}

\author{
Nnane EBAH Ndode \\ Institution \\ Government Bilingual High school Muea-Buea \\ Ministry of secondary education, Cameroon
}

\begin{abstract}
This paper is aimed at bringing out the burning desire and need for the globalisation of teaching and learning methodologies in secondary education.Globalisation has many definations but will limit myself to that of Martin Albrow(1990), which defines globalisation as all those processes by which the people of the world are incorporated into a single world society,global society. And in this 21 st century this defination cannot be conplete without making mention of education(Art of teaching and learning).Regreatably,there is little or no effort towards the globalisation of the teaching and learning methodologies in secondary education across the globe. The information in this Article was obtained through review of literature;articles published in peer review journals from the search engines and published books. The objective is therefore to argue the fact that with a globalised teaching and learning methodologies in secondary education,the following amongst others will be attained.1)A sound education of high quality and competativeness in a globally unified front.2)The eminent creation of a global village and why not a global citizen.The paper concludes that as a challange to globalisation of this art,education stakeholders will need to rethink the ways it can be harmonised in the secondry education.Also considering that global issues do challange secondary education on a daily basis,its teaching and learning methodologies can no longer be perceived in a strickly national context.
\end{abstract}

Keywords: Global citizen; harmonised; national context; single world society; stakeholders 